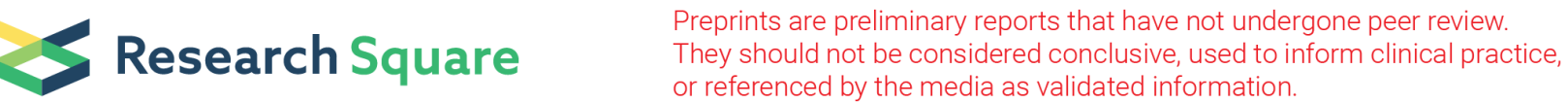

\section{Impact of Neutrophil-Lymphocyte Ratio on Long- term Outcomes of Patients with Coronary Chronic Total Occlusion After Percutaneous Coronary Intervention}

\section{Ke Gao}

Xi'an Jiaotong University Medical College First Affiliated Hospital

\section{Bo-Lin Li}

Xi'an Jiaotong University

\section{Lei Yang}

Xi'an Jiaotong University Medical College First Affiliated Hospital

\section{Yan-Bo Xue}

Xi'an Jiaotong University

\section{Wan-Ying Yang}

Xi'an Jiaotong University

\section{Yue Wu}

Xi'an Jiaotong University

Xiao-pu Zheng ( $\square$ zhengxp0001@163.com )

Xi'an Jiaotong University https://orcid.org/0000-0001-9850-2014

Research article

Keywords: neutrophil-lymphocyte ratio, coronary chronic total occlusion, major adverse cardiac events

Posted Date: June 4th, 2020

DOI: https://doi.org/10.21203/rs.3.rs-32638/v1

License: (9) (i) This work is licensed under a Creative Commons Attribution 4.0 International License. Read Full License 


\section{Abstract}

Background: The impact of preprocedural neutrophil-lymphocyte ratio (NLR) level on subsequent adverse cardiovascular events and health status in coronary chronic total occlusion (CTO) patients after stent implantation is unclear. The present study aims to evaluate the impact of NLR level on long-term clinical outcomes and health status of CTO patients after percutaneous coronary intervention ( $\mathrm{PCl})$ in the drug eluting stent era.

Methods: A total of 311 CTO patients who underwent successful PCl with new-generation drug-eluting stent and with follow-up were enrolled. Patients were classified into 3 groups according to the tertiles of NLR level at baseline. The primary endpoint (major adverse cardiac events, MACE) was a composite of cardiac death, target-vessel myocardial infarction (MI), and ischemia-driven target-vessel revascularization (TVR) on follow-up. Multivariable COX regression analysis was performed to estimate the relationships between the parameters and MACE.

Results: Compared with the low and intermediate tertile groups, preprocedural platelet-lymphocyte ratio (PLR) level and age were significantly higher in the high NLR tertile group. After a median follow-up of 32 (interquartile range: 20 to 44 ) months, MACE was observed in 10 patients $(9.7 \%)$ in the low tertile, in 21 (20.2\%) in the intermediate tertile, and in $31(29.8 \%)$ in the high tertile group $(P=0.001)$. Kaplan-Meier analysis demonstrated a significantly higher incidence of MACE, mainly driven by TVR, in patients with high tertile than the low and intermediate tertile groups. Multivariable COX regression analysis showed NLR and occluded length as independent predictors of MACE. No statistically differences were observed regarding the five domains of Seattle Angina Questionnaire (SAQ) scores among the 3 groups (all $P>$ $0.05)$.

Conclusions: In conclusion, in patients who underwent PCI for CTO lesions, elevated NLR level was independently associated with MACE (driven by TVR) on follow-up.

\section{Background}

Chronic total occlusion (CTO) in coronary arteries is considered as the final stage of coronary atherosclerosis, and these complex lesions are identified in approximately $15-30 \%$ of all coronary angiography $[1,2]$. Percutaneous coronary intervention (PCI) for CTO lesions is one of the major technical challenges in contemporary interventional cardiology. With the remarkable developments in interventional techniques in the last few years, the procedural success rate and safety of $\mathrm{PCl}$ in patients with CTO has improved [3-5]. Furthermore, successful PCI for CTO has been shown to reduce the risk of cardiac death, post-operative myocardial infarction (MI), and improves long-term survival compared with failed CTO PCI [6-8]. However, even after successful revascularization, the long term clinical outcomes of CTO patients were still unsatisfactory, and it has been identified as an independent predictor of the need for targetvessel revascularization (TVR) and subsequent adverse cardiac outcomes after CTO PCI $[9,10]$. Thus, 
attention has shifted to underlie the pathophysiology of atherosclerosis, and the influence of early biomarkers on CTO patient's prognosis is worthy of exploration.

Inflammation is a central factor for the initiation and progression of coronary atherosclerosis $[11,12]$. Several inflammatory biomarkers, such as white blood cell count, red cell distribution width (RDW), neutrophil-lymphocyte ratio (NLR), platelet-lymphocyte ratio (PLR), high-sensitivity C-reactive protein (hs$\mathrm{CRP}$ ) and mean platelet volume (MPV) have been associated with coronary artery disease (CAD) [12, 13]. More recently, it has been demonstrated that NLR level is associated with the prevalence and severity of $C A D$, and the elevated NLR predicts the risk of adverse cardiac events in acute coronary syndrome patients $[14,15]$. Additionally, higher baseline NLR level was risk factor for the development of in-stent restenosis in CTO patients after $\mathrm{PCl}[16]$.

To date, few reports have evaluated the impact of preprocedural NLR level on major adverse cardiac events (MACE) at long-term follow-up in CTO patients after stent implantation, especially in Chinese individuals. Similarly, the long-term health status quantified by the Seattle Angina Questionnaire (SAQ) of this patient subgroup are poorly characterized. The aim of this study was to address these important questions.

\section{Methods}

\section{Study populations}

493 patients with CTO lesions were confirmed by coronary angiography in the Cardiology Department of the First Affiliated Hospital of Xi'an JiaoTong University (Xi'an, Shaanxi, China) undergoing PCI between June 2013 and October 2017. The inclusion criteria for the present study were: 1) only 1 CTO lesion per patient detected on diagnostic coronary angiography; 2) symptomatic angina and/or functional ischemia. Exclusion criteria were: 1) patients with signs of inflammation; 2) history of cardiogenic shock or cardiopulmonary resuscitation; 3 ) a self-identified history of stroke, renal failure or severe arrhythmia; 4) also had a malignant tumor; 5)previous coronary artery bypass graft surgery. Of these 493 patients, 182 were excluded because of unsuccessful PCl operation $(n=117)$, missing laboratory values $(n=27)$ or clinical follow-up data $(n=38)$, resulting in a study population of 311 patients who underwent successful $\mathrm{PCl}$ and follow-up. They were classified into 3 groups according to tertiles of NLR level. The periodic follow-up for adverse events were carried out via telephone contacts or outpatient visit every year between 2014 and 2018. The study was approved by both Research and Ethics Committees of the First Affiliated Hospital of Xi'an JiaoTong University.

\section{Definitions}

A "CTO lesion" was defined as $100 \%$ luminal obstruction with an estimated duration of occlusion of at least 3 months with no antegrade flow through the lesion (TIMI 0 flow) $[1,4]$. The estimated duration of occlusion was based on the first onset of angina, previous history of myocardial infarction (MI) in the 
target vascular region or proven by prior angiographic results. Technical success was defined as residual stenosis of less than $30 \%$ with antegrade flow TIMI 3. Procedural success was defined as technical success plus no in-hospital adverse cardiac effects, including Ml, all-cause mortality and recurrence of cardiac symptoms requiring repeat target vessel PCI $[4,10]$. The clinical endpoint of MACE on follow-up were defined as a composite of target-vessel MI, cardiac death, and ischemia-driven TVR in the treated CTO vessel $[6,10]$. All deaths were considered to have been from cardiac causes unless a explicit noncardiac cause could be documented. According to the fourth universal definition of Ml criteria [17], MI was defined as an increase in creatine kinase-MB fraction or troponin-T/troponin-l to $>3$ times the upper limit of reference value with ischemic symptoms or electrocardiographic findings indicative of ischemia.

\section{Seattle Angina Questionnaire}

A total of 287 patient' views on their health status have been quantified by the SAQ Scores at the last follow-up. As shown in Table 6, no statistically differences were observed regarding physical limitation, angina frequency, angina stability, treatment satisfaction and quality of life among the 3 groups (all $P>$ 0.05). Pearson correlation analysis indicated that there were no significant relationships between NLR level and SAQ scores in the five domains (Data not shown).

Table 6

Seattle Angina Questionnaire scores on follow-up

\begin{tabular}{|llllll|}
\hline Variable & All & Low & Intermediate & High & $P$ \\
& $(\mathbf{n = 2 8 7 )}$ & $(\mathbf{n = 1 0 0 )}$ & $(\mathbf{n = 9 4 )}$ & $(\mathbf{n = 9 3 )}$ & \\
\hline Physical limitation scale & $51.0 \pm 17.0$ & $50.4 \pm 15.9$ & $48.8 \pm 18.2$ & $54.2 \pm 16.7$ & 0.098 \\
\hline Angina stability scale & $75.3 \pm 28.0$ & $76.8 \pm 28.6$ & $74.7 \pm 28.7$ & $74.1 \pm 26.8$ & 0.792 \\
\hline Angina frequency scale & $91.6 \pm 15.6$ & $90.9 \pm 19.1$ & $92.3 \pm 12.8$ & $91.5 \pm 14.3$ & 0.833 \\
\hline Treatment satisfaction scale & $70.7 \pm 13.6$ & $71.3 \pm 14.8$ & $70.4 \pm 13.5$ & $70.4 \pm 12.2$ & 0.879 \\
\hline Quality of Life & $74.9 \pm 15.3$ & $75.1 \pm 14.9$ & $76.6 \pm 13.8$ & $72.7 \pm 17.3$ & 0.257 \\
\hline Data are presented as mean \pm standard deviation. & & & \\
\hline
\end{tabular}

\section{Measurements Of Related Parameters}

We collected several demographics, clinical and analytical parameters. Age, gender, height and weight were recorded. Patients either with persistent blood pressure $>140 / 90 \mathrm{mmHg}$ or those currently taking antihypertensive drugs were considered hypertensive. Several biochemical parameters, including serum uric acid, lipid profiles, plasma homocysteine, hs-CRP and estimated glomerular filtration rate (eGFR) were measured. Total white blood cells, neutrophil, lymphocyte, and platelet counts, RDW, MPV were calculated using an automated blood cell counter (Model XE2100; Sysmex, Kobe, Japan). The NLR was 
computed using the absolute neutrophil count divided by the lymphocyte count, the PLR was calculated by dividing the platelet count by the absolute lymphocyte count [16].

\section{Statistical analysis}

Data are presented as means \pm standard deviation or median and interquartile range for continuous variables and percentages for categorical variables. Continuous variables that had a normal distribution were evaluated using analysis of variance (ANOVA), whereas the Kruskal-Wallis test was used for nonnormally distributed data. Categorical variables and frequencies were compared with the chi-squared test. Pearson correlation analysis was used to analyze the relationship between NLR and SAQ scores. The clinical outcomes occurring over time for MACE were described by Kaplan-Meier survival curves and compared by the log-rank test. Univariable COX regression analysis was used to explore the association between the variables and MACE, hypertension, diabetes mellitus and variables with $P<0.10$ were included in the multivariable COX regression analysis. Strengths of associations were determined by estimating the hazard ratios (HRs) and their 95\% confidence intervals (95\% Cls). The predictive values of NLR in MACE was tested using receiver operating characteristic (ROC) analysis. In all cases, $P<0.05$ was considered significant. All statistical analysis was performed retrospectively with SPSS 25.0 (SPSS, Inc., Chicago, IL) and R 3.1.0 (R Foundation for Statistical Computing).

\section{Results}

\section{Study Population and Baseline Characteristics}

A total of 311 patients with CTO (mean age: $67.6 \pm 9.9$ years; $82.3 \%$ men) were divided into tertiles according to baseline NLR level. The tertiles of NLR level were as follows: low tertile, $\leq 2.0$; intermediate tertile, 2.1 to 3.2; and high tertile, $\geq 3.2$. Baseline clinical characteristics and preoperative laboratory results of all subjects are summarized in Table 1 and Table 2. Compared with patients in the low and intermediate tertile groups, preprocedural PLR level and age were significantly higher in the high tertile group. However, patients with high tertile of NLR level had a lower left ventricular ejection fraction than other patients at admission. There were no statistically significant differences in the oral administration of cardiovascular drugs, white blood cell count, lipid profiles, eGFR and hs-CRP level among the 3 groups (all $P>0.05$ ). Table 3 presents the angiographic and procedural characteristics of all CTO patients who underwent successful PCl and follow-up. No differences were observed regarding number of diseased vessels, the target CTO vessel, collateral flow, occluded length and the severity of calcification. All patients in the present study received a second generation drug-eluting stents, there were no significant differences in stent parameters among these groups. 
Table 1

Baseline Clinical Characteristics

\begin{tabular}{|c|c|c|c|c|c|}
\hline Variable & $\begin{array}{l}\text { All } \\
(n=311)\end{array}$ & $\begin{array}{l}\text { Low } \\
(n=103)\end{array}$ & $\begin{array}{l}\text { Intermediate } \\
(n=104)\end{array}$ & $\begin{array}{l}\text { High } \\
(n=104)\end{array}$ & $P$ \\
\hline Age (yrs) & $67.6 \pm 9.9$ & $\begin{array}{l}64.5 \pm \\
10.8\end{array}$ & $68.5 \pm 9.9$ & $69.8 \pm 8.3$ & 0.004 \\
\hline Men, n (\%) & $256(82.3)$ & $82(79.6)$ & $83(79.8)$ & $91(87.5)$ & 0.236 \\
\hline Body mass index $\left(\mathrm{kg} / \mathrm{m}^{2}\right)$ & $23.6 \pm 5.9$ & $24.2 \pm 5.9$ & $22.4 \pm 6.6$ & $24.2 \pm 4.8$ & 0.090 \\
\hline Current smoker, n (\%) & $147(47.3)$ & $49(47.6)$ & $50(48.1)$ & $48(46.2)$ & 0.959 \\
\hline Hypertension, n (\%) & $89(28.6)$ & $25(24.3)$ & $31(29.8)$ & $33(31.7)$ & 0.468 \\
\hline Diabetes mellitus, n (\%) & $68(21.9)$ & $17(16.5)$ & $25(24.0)$ & $26(25.0)$ & 0.270 \\
\hline Prior myocardial infarction, n (\%) & $117(37.6)$ & $38(36.9)$ & $39(37.5)$ & $40(38.5)$ & 0.973 \\
\hline \multicolumn{6}{|l|}{$\begin{array}{l}\text { Cardiovascular medications, } \mathrm{n} \\
(\%)\end{array}$} \\
\hline DAPT & $282(90.6)$ & $91(88.3)$ & $96(92.3)$ & $95(91.2)$ & 0.748 \\
\hline Statins & $311(100)$ & $103(100)$ & $104(100)$ & $104(100)$ & - \\
\hline Beta-blockers & $268(86.2)$ & $93(90.3)$ & $89(85.6)$ & $86(82.6)$ & 0.448 \\
\hline ACEI/ARB & $264(84.9)$ & $91(88.3)$ & $85(81.7)$ & $88(84.6)$ & 0.566 \\
\hline Calcium channel blocker & $61(19.6)$ & $20(19.4)$ & $21(20.1)$ & $20(19.2)$ & 1.000 \\
\hline Nitrate & $69(22.2)$ & $15(14.4)$ & $28(26.9)$ & $26(25.0)$ & 0.206 \\
\hline Ejection fraction, (\%) & $\begin{array}{l}55.8 \pm \\
13.0\end{array}$ & $\begin{array}{l}58.4 \pm \\
12.2\end{array}$ & $56.0 \pm 12.8$ & $53.1 \pm 13.7$ & 0.035 \\
\hline \multicolumn{6}{|c|}{ Data are presented as $n(\%)$, mean \pm standard deviation. } \\
\hline
\end{tabular}


Table 2

Results of Preoperative Laboratory Measurements

\begin{tabular}{|c|c|c|c|c|c|}
\hline Variable & $\begin{array}{l}\text { All } \\
(n=311)\end{array}$ & $\begin{array}{l}\text { Low } \\
(n=103)\end{array}$ & $\begin{array}{l}\text { Intermediate } \\
(n=104)\end{array}$ & $\begin{array}{l}\text { High } \\
(n=104)\end{array}$ & $P$ \\
\hline Hemoglobin (g/L) & $\begin{array}{l}137.4 \pm \\
19.7\end{array}$ & $\begin{array}{l}137.9 \pm \\
16.1\end{array}$ & $138.3 \pm 19.3$ & $\begin{array}{l}135.9 \pm \\
23.1\end{array}$ & 0.647 \\
\hline RDW (\%) & $13.3 \pm 1.5$ & $13.3 \pm 2.3$ & $13.3 \pm 0.8$ & $\begin{array}{l}13.3 \pm \\
1.2\end{array}$ & 0.985 \\
\hline PLT $\left(10^{9} / \mathrm{L}\right)$ & $\begin{array}{l}179.7 \pm \\
55.2\end{array}$ & $\begin{array}{l}184.3 \pm \\
54.0\end{array}$ & $181.2 \pm 54.2$ & $\begin{array}{l}173.6 \pm \\
57.4\end{array}$ & 0.356 \\
\hline MPV (fl) & $11.5 \pm 1.3$ & $11.4 \pm 1.3$ & $11.6 \pm 1.3$ & $\begin{array}{l}11.6 \pm \\
1.2\end{array}$ & 0.705 \\
\hline PLR & $\begin{array}{l}124.7 \pm \\
46.1\end{array}$ & $\begin{array}{l}94.7 \pm \\
30.3\end{array}$ & $115.0 \pm 37.9$ & $\begin{array}{l}164.0 \pm \\
57.6\end{array}$ & 0.000 \\
\hline White blood cell $\left(10^{9} / \mathrm{L}\right)$ & $6.3 \pm 1.8$ & $6.0 \pm 1.9$ & $6.3 \pm 1.7$ & $6.6 \pm 1.7$ & 0.083 \\
\hline $\mathrm{HbA1c}(\%)$ & $6.0 \pm 2.1$ & $5.9 \pm 2.1$ & $6.1 \pm 2.0$ & $6.2 \pm 2.1$ & 0.439 \\
\hline Serum uric acid ( $\mu \mathrm{mol} / \mathrm{L})$ & $\begin{array}{l}346.2 \pm \\
93.6\end{array}$ & $\begin{array}{l}354.5 \pm \\
91.6\end{array}$ & $340.3 \pm 94.8$ & $\begin{array}{l}343.8 \pm \\
94.5\end{array}$ & 0.523 \\
\hline eGFR $\left(\mathrm{mL} / \mathrm{min} / 1.73 \mathrm{~m}^{2}\right)$ & $\begin{array}{l}93.9 \pm \\
27.9\end{array}$ & $\begin{array}{l}99.4 \pm \\
30.0\end{array}$ & $91.4 \pm 27.3$ & $\begin{array}{l}90.8 \pm \\
25.9\end{array}$ & 0.168 \\
\hline Cystatin C (mg/L) & $0.9 \pm 0.3$ & $0.9 \pm 0.3$ & $1.0 \pm 0.3$ & $0.9 \pm 0.3$ & 0.836 \\
\hline Total cholesterol (mmol/L) & $3.8 \pm 0.9$ & $3.8 \pm 0.9$ & $3.8 \pm 0.9$ & $3.8 \pm 1.0$ & 0.989 \\
\hline Total triglycerides (mmol/L) & $1.8 \pm 0.5$ & $2.0 \pm 0.4$ & $1.7 \pm 0.9$ & $1.6 \pm 0.8$ & 0.100 \\
\hline $\begin{array}{l}\text { Low-density lipoprotein } \\
\text { Cholesterol (mmol/L) }\end{array}$ & $2.2 \pm 0.8$ & $2.2 \pm 0.8$ & $2.1 \pm 0.8$ & $2.2 \pm 0.9$ & 0.793 \\
\hline $\begin{array}{l}\text { High-density lipoprotein cholesterol } \\
(\mathrm{mmol} / \mathrm{L})\end{array}$ & $1.1 \pm 0.3$ & $1.1 \pm 0.6$ & $1.2 \pm 0.3$ & $1.0 \pm 0.2$ & 0.341 \\
\hline Hcy (umol/L) & $\begin{array}{l}20.7 \pm \\
13.0\end{array}$ & $\begin{array}{l}20.3 \pm \\
12.8\end{array}$ & $19.4 \pm 12.5$ & $\begin{array}{l}22.3 \pm \\
13.8\end{array}$ & 0.338 \\
\hline $\mathrm{Hs}-\mathrm{CRP}(\mathrm{mg} / \mathrm{L})$ & $3.0 \pm 0.4$ & $2.7 \pm 0.3$ & $3.0 \pm 0.5$ & $3.3 \pm 0.6$ & 0.626 \\
\hline \multicolumn{6}{|c|}{ Data are presented as mean \pm standard deviation. } \\
\hline $\begin{array}{l}\text { RDW: red cell distribution width; } \mathrm{PL} \\
\text { ratio; HbA1c: glycated hemoglobin; } \\
\text { CRP: high-sensitivity C-reactive prot }\end{array}$ & $\begin{array}{l}\text { elet; MPV } \\
\text { estimate }\end{array}$ & $\begin{array}{l}\text { ean plate } \\
\text { omerular }\end{array}$ & $\begin{array}{l}\text { lume; PLR: } \\
\text { tion rate; } \mathrm{H}\end{array}$ & $\begin{array}{l}\text { let-lymp } \\
\text { omocys }\end{array}$ & $\begin{array}{l}\text { cyte } \\
\text { e; hs- }\end{array}$ \\
\hline
\end{tabular}


Table 3

Angiographic and Procedural Characteristics

\begin{tabular}{|c|c|c|c|c|c|}
\hline Variable & $\begin{array}{l}\text { All } \\
(n=311)\end{array}$ & $\begin{array}{l}\text { Low } \\
(n=103)\end{array}$ & $\begin{array}{l}\text { Intermediate } \\
(n=104)\end{array}$ & $\begin{array}{l}\text { High } \\
(n=104)\end{array}$ & $P$ \\
\hline \multicolumn{6}{|l|}{ Number of diseased vessels, $\mathrm{n}(\%)$} \\
\hline 1 & $36(11.6)$ & $15(14.6)$ & $8(7.7)$ & $13(12.5)$ & 0.282 \\
\hline 2 & $38(12.2)$ & $16(15.5)$ & $13(12.5)$ & $9(8.7)$ & \\
\hline 3 & $\begin{array}{l}237 \\
(76.2)\end{array}$ & $72(69.9)$ & $83(79.8)$ & $82(78.8)$ & \\
\hline Number of CTOs & 311 & 103 & 104 & 104 & - \\
\hline \multicolumn{6}{|l|}{ Target-vessel СTO, n (\%) } \\
\hline Right coronary artery & $\begin{array}{l}139 \\
(44.7)\end{array}$ & $48(46.6)$ & $46(44.2)$ & $45(43.3)$ & 0.712 \\
\hline Left anterior descending & $\begin{array}{l}104 \\
(33.4)\end{array}$ & $36(35.0)$ & $31(29.8)$ & $37(35.6)$ & \\
\hline Left circumflex & $68(21.9)$ & $19(18.4)$ & $27(26.0)$ & $22(21.2)$ & \\
\hline collateral flow, n (\%) & $\begin{array}{l}116 \\
(37.3)\end{array}$ & $35(33.9)$ & $50(48.0)$ & $31(29.8)$ & 0.092 \\
\hline Occluded length (mm) & $18.9 \pm 6.6$ & $18.4 \pm 8.2$ & $17.5 \pm 5.9$ & $20.4 \pm 5.5$ & 0.395 \\
\hline $\begin{array}{l}\text { Moderate or severe calcifications, } n \\
(\%)\end{array}$ & $98(31.5)$ & $34(33.0)$ & $33(31.7)$ & $31(29.8)$ & 0.871 \\
\hline J-CTO score & $\begin{array}{l}1.91 \pm \\
1.19\end{array}$ & $\begin{array}{l}1.89 \pm \\
1.15\end{array}$ & $1.95 \pm 1.23$ & $\begin{array}{l}1.91 \pm \\
1.20\end{array}$ & 0.341 \\
\hline Retrograde approach, n (\%) & $73(23.5)$ & $22(21.3)$ & $24(23.1)$ & $27(26.0)$ & 0.690 \\
\hline Number of stents implanted & $2.1 \pm 0.7$ & $2.1 \pm 0.8$ & $2.1 \pm 0.7$ & $2.1 \pm 0.6$ & 0.941 \\
\hline Total stent length $(\mathrm{mm})$ & $39.0 \pm 7.5$ & $38.4 \pm 8.2$ & $38.1 \pm 6.9$ & $40.8 \pm 7.5$ & 0.670 \\
\hline Stent diameter (mm) & $\begin{array}{l}2.95 \pm \\
0.41\end{array}$ & $\begin{array}{l}3.00 \pm \\
0.36\end{array}$ & $2.94 \pm 0.40$ & $\begin{array}{l}2.90 \pm \\
0.47\end{array}$ & 0.742 \\
\hline \multicolumn{6}{|c|}{ Data are presented as $n(\%)$, mean \pm standard deviation. } \\
\hline onic total occlusion; J-CT & nese-C & & & & \\
\hline
\end{tabular}

\section{Clinical Outcomes In Total Population}


The median follow-up period was 32 months (interquartile range:20 to 44 months). The clinical outcomes of all CTO patients on follow-up are shown in Table 4. The overall number of MACE was 62/311 (19.9\%), and MACE was observed in 10 patients (9.7\%) in the low tertile, in $21(20.2 \%)$ in the intermediate tertile, and in $31(29.8 \%)$ in the high tertile group $(P=0.001)$. The incidence of ischemia-driven TVR was significant higher in patients with high tertile of NLR $(21.2 \%, P=0.004)$. No differences were observed regarding cardiac death, target-vessel $\mathrm{MI}$ between groups (all $P>0.05$ ). Kaplan-Meier analysis demonstrated a significantly higher incidence of MACE, driven by TVR, in patients with high tertile than the low and intermediate groups (Log Rank 16.11 and 19.99, all $P<0.001$, Fig. 1 and Fig. 2).

Table 4

Clinical Outcomes on Follow-Up in All Study Patients

\begin{tabular}{|llllll|}
\hline Variable & All & Low & Intermediate & High & $P$ \\
& $(\mathbf{n = 3 1 1 )}$ & $(\mathbf{n = 1 0 3 )}$ & $(\mathbf{n = 1 0 4 )}$ & $(\mathbf{n = 1 0 4 )}$ & \\
\hline MACE, n (\%) & $62(19.9)$ & $10(9.7)$ & $21(20.2)$ & $31(29.8)$ & 0.001 \\
\hline cardiac mortality, n (\%) & $24(7.7)$ & $3(2.9)$ & $10(9.6)$ & $11(10.6)$ & 0.053 \\
\hline target-vessel MI, n (\%) & $25(8.0)$ & $5(4.9)$ & $9(8.7)$ & $11(10.6)$ & 0.305 \\
\hline ischemia-driven TVR, n (\%) & $40(6.0)$ & $6(5.8)$ & $12(11.5)$ & $22(21.2)$ & 0.004 \\
\hline Data are presented as n (\%). & & & & \\
\hline MACE: major adverse cardiac events;Ml: myocardial infarction; TVR: target-vessel revascularization. \\
\hline
\end{tabular}

\section{Predictors Of Adverse Cardiovascular Events}

In multivariable COX regression analysis to determine the predictors of MACE, NLR (HR: $1.506 ; 95 \% \mathrm{Cl}$ : 1.143-1.984; $P=0.004$ ), longer occluded length (HR: 1.208; 95\% Cl: $1.045-1.397 ; P=0.011)$ and lower left ventricular ejection fraction (HR: $0.962 ; 95 \% \mathrm{Cl}$ : 0.935-0.990; $P=0.008)$ were independent predictors for MACE in patients with CTO lesions (Table 5). According to Receiver Operating Characteristic (ROS) analysis, NLR with a cutoff value of 2.43 was predictive of MACE occurrence with $83.3 \%$ sensitivity and $64.3 \%$ specificity (area under the curve $[\mathrm{AUC}]=0.720 ; P=0.020 ; 95 \% \mathrm{Cl}: 0.572-0.872 ;$ Figure S1). 
Table 5

Predictors of Major Adverse Cardiac Events

\begin{tabular}{|c|c|c|c|c|}
\hline \multirow[t]{2}{*}{ Variable } & \multicolumn{2}{|l|}{ Univariable } & \multicolumn{2}{|l|}{ Multivariable } \\
\hline & $\mathrm{HR}(95 \% \mathrm{Cl})$ & $P$ & $\mathrm{HR}(95 \% \mathrm{Cl})$ & $P$ \\
\hline Age & $1.047(1.015-1.080)$ & 0.004 & $1.047(0.994-1.102)$ & 0.081 \\
\hline Men & $1.005(0.485-2.082)$ & 0.990 & & \\
\hline Hypertension & $1.026(0.555-1.894)$ & 0.936 & $0.983(0.445-2.174)$ & 0.967 \\
\hline Diabetes mellitus & $1.467(0.776-2.774)$ & 0.239 & $0.749(0.330-1.699)$ & 0.489 \\
\hline NLR & $1.331(1.148-1.544)$ & 0.000 & $1.506(1.143-1.984)$ & 0.004 \\
\hline PLR & $1.004(0.999-1.008)$ & 0.103 & $0.995(0.988-1.003)$ & 0.247 \\
\hline RDW & $1.080(0.924-1.261)$ & 0.335 & & \\
\hline MPV & $0.814(0.618-1.073)$ & 0.144 & & \\
\hline hsCRP & $1.055(0.963-1.154)$ & 0.250 & & \\
\hline eGFR $\left(\mathrm{ml} / \mathrm{min} / 1.73 \mathrm{~m}^{2}\right)$ & $0.986(0.974-0.999)$ & 0.034 & $0.996(0.980-1.012)$ & 0.621 \\
\hline Serum uric acid & $1.000(0.997-1.003)$ & 0.842 & & \\
\hline Occluded length (mm) & $1.153(1.030-1.291)$ & 0.010 & $1.208(1.045-1.397)$ & 0.011 \\
\hline Ejection fraction (\%) & $0.956(0.935-0.977)$ & 0.000 & $0.962(0.935-0.990)$ & 0.008 \\
\hline
\end{tabular}

\section{Discussion}

The study was designed to evaluate the impact of NLR level on long-term clinical outcomes defined as MACE and health status of CTO patients after PCl in the drug eluting stent era. The findings of the study were as follows: 1) patients in the high tertile group (NLR > 3.2) had a higher rate of MACE than those in the low tertile and the intermediate tertile group at long period of follow-up; 2) elevated preprocedural NLR level was independently associated with MACE, mainly driven by TVR, on follow-up; 3) There were no differences in the long-term health status quantified by SAQ scores of CTO patients regardless of the NLR level.

Prior to the advancement of technique and devices for CTO PCI, CTO lesion is still a challenging subset for successful CTO revascularization. PCI for CTO patients was associated with lower procedural success rates and higher risk of operative complications than those with less complex lesions [19]. With the improvement of technique and equipment for CTO revascularization, such as the retrograde approach, 
CrossBoss catheter and dissection and re-entry techniques, success rates of CTO PCI have remarkably increased [3, 5, 20]. Moreover, new anti-ischemic drugs, drug-eluting stents, potent antiplatelet agents, and high-dose statins have contributed to reduce the progression of cardiovascular disease and atherosclerosis. However, CTO and in-stent restenosis have been shown to be a worsening clinical condition $[9,10,21]$. The successful treatment of CTO lesion was a strong predictor of subsequent adverse events, including cardiac death, ischemia or symptoms-driven TVR, and CTO PCl was not associated with a reduction in long-term MACE $[10,21]$. The pathophysiological mechanism of such recurrent events after $\mathrm{PCI}$ for CTO is largely unknown. Therefore, attention has shifted to underlie the pathophysiology of atherosclerosis, and there is a need to identify new markers to accurately predict the prognosis of CTO patients and allow better risk stratification.

Indeed, inflammation plays an indispensable role in the pathogenesis of atherosclerosis, and an elevation in inflammatory biomarkers represents the activation of coronary artery damage [14]. Mounting evidence suggests that inflammation, including pre-existing systemic inflammation, local vascular inflammation secondary to $\mathrm{PCl}$, plays a central role in promoting neointimal growth and in-stent restenosis [16, 22]. After stenting for СTO lesions, platelet and fibrin are deposited around the stents. An acute inflammation response secondary to mechanical injury inflicted by revascularization leads to endothelial rupture and dysfunction, plaque rupture and platelet activation [16]. And this initial acute inflammation is followed by granulation tissue reactions, including migration and proliferation of smooth muscle cells, neovascularization and chronic inflammatory cell infiltration occurs within a few weeks, which causes neointimal hyperplasia, atherosclerosis and in-stent restenosis [16, 22, 23]. Because inflammation plays an important role in the atherosclerosis process, there is increasing interest in various inflammatory biomarkers. Inflammation has been associated with many diseases, such as acute myocardial infarction, chronic heart failure, metabolic disorders, cancer and other cardiovascular disease [12, 24, 25]. Currently, many inflammatory biomarkers have been used to investigate the relationship between inflammatory response and CAD, including white blood cell count, hs-CRP, PLR, NLR, MPV and interleukin-1 [12-14, 16]. Furthermore, unlike several comorbidities and cardiovascular risk factors used by the Framingham Coronary Heart Disease Risk Score and the Atherosclerotic Cardiovascular Disease Risk Algorithm [26], some researchers have studied potential novel risk scores that also include inflammatory markers, such as the PLR and NLR values, which have also provided useful information for predicting cardiovascular events in patients with CAD $[16,27,28]$.

Recently, NLR has been considered as a potential marker of inflammation in cardiovascular diseases. Neutrophils secrete a variety of inflammatory mediators, which can cause endothelial injury and vascular wall degeneration. Lymphocytes have an anti-atherosclerotic role and regulate the inflammatory response. Consequently, a high NLR represents two immune pathways, making it more predictive than the method used to evaluate either parameter individually [23, 29]. Several studies have shown that the white blood cell count and its subtypes, neutrophils and lymphocytes, were associated with the prevalence and severity of CAD and its prognosis $[14,15,28,30]$. Meta-analysis shows that NLR was an independent predictor of hospitalization, long-term cardiovascular events and cardiac mortality in patients with STsegment elevation $\mathrm{MI}$ after $\mathrm{PCl}$ [31]. Arbel $\mathrm{Y}$ et al. reported that in patients with ST-segment elevation MI, 
higher NLR was independently associated with lower left ventricular ejection fraction and higher all-cause mortality up to 5 years[30]. Therefore, NLR appears to be an effective marker of systemic inflammation and was considered to be a predictor for worse clinical outcomes under different conditions, including acute coronary syndrome, ST-segment elevation $\mathrm{Ml}$ and in-stent restenosis.

However, few reports have evaluated the impact of preprocedural NLR level on subsequent adverse cardiovascular events at long-term follow-up in CTO patients after stent implantation. Elevated NLR level was reportedly associated with the impaired development of coronary collaterals in CTO patients [32]. Li $\mathrm{C}$ et al. observed that preprocedural NLR level was a powerful risk factor for early in-stent restenosis in patients who underwent successful PCI for CTO lesions [16]. To our knowledge, only one study showed that $\mathrm{NLR}_{\triangle}$, defined as the change of NLR level between on admission and post-PCl, was independently associated with higher risks of in-stent restenosis and MACE in 160 CTO patients at 1-year follow-up [33]. However, the $\mathrm{NLR}_{\triangle}$ level may be involved in vascular mechanical injury secondary to $\mathrm{PCl}$. After a median follow-up of 32 months, we found that in CTO patients who underwent successful PCl, the incidence of MACE in high NLR tertile group was significantly higher than those in the other groups, and elevated preprocedural NLR level was independent predictor for long-term MACE in patients with CTO lesions.

No studies have quantified the impact of preprocedural NLR level on the long-term health status quantified by the SAQ scores after PCI for CTO patients. The SAQ, which quantifies five domains to measure the impact of CAD on patients' health status, has been shown to be effective, reproducible, and sensitive to changes in clinical symptoms [34,35]. Safley et al. reported that all SAQ scores improved after PCl for CTO and non-CTO patients, and there were no difference in Physical Limitation, Quality of Life and Angina Frequency scores between groups [36]. Ybarra et al. observed that CTO patients with complex features such as those with dissection re-entry techniques, those with high complexity (Japanese CTO $\geq 3$ ) or coronary artery bypass grafting had a similar degree of improvement in health status quantified by the SAQ Scores when compared with those with less complex CTOs [37]. In our study, we first found that there were no significant differences regarding physical limitation, angina frequency, angina stability, treatment satisfaction and quality of life among the 3 groups, and the preprocedural NLR level was not associated with SAQ scores in the five domains. Therefore, the preprocedural NLR level had no effect on the long-term health status quantified by the SAQ scores of CTO patients after $\mathrm{PCl}$.

Our study has several limitations. First of all, it shares all the limitations of observational, single center studies. Second, although there were no statistically significant differences in most potential confounding factors among the 3 groups, we were unable to correct for unmeasured potential variables. Third, this was a retrospective study unpowered to identify all changes to patients' medical treatment strategies during follow-up. Finally, the sample size was limited, so this study was considerably underpowered, and our results might not be generalizable to other studies.

\section{Conclusions}


In conclusion, the present study suggests that NLR value appears additive to conventional cardiovascular risk factors and commonly used biomarkers in predicting MACE after PCI for CTO. A collaborative, largersample and multicenter study is needed to investigate the potential predictive value of baseline and postoperative inflammatory biomarker levels for long-term outcomes in patients with CTO lesions after $\mathrm{PCl}$.

\section{Abbreviations}

CAD

Coronary artery disease; Cl:Confidence interval; CTO:Chronic total occlusion; eGFR:estimated glomerular filtration rate; HR:Hazard ratio; hs-CRP:High-sensitivity C-reactive protein; MPV:MACE:Major adverse cardiac events; Mean platelet volume; MI:Myocardial infarction; NLR:Neutrophil-lymphocyte ratio; PCI:Percutaneous coronary intervention; PLR:Platelet-lymphocyte ratio; RDW:Red cell distribution width; SAQ:Seattle Angina Questionnaire; TVR:Target-vessel revascularization;

\section{Declarations}

\section{Ethics approval and consent to participate}

The study was approved by both Research and Ethics Committees of the First Affiliated Hospital of Xi'an JiaoTong University. All participants gave written informed consent after thorough explanation of the procedures involved.

\section{Consent for publication}

Not applicable.

\section{Availability of data and materials}

All relevant data supporting the conclusions of this article is included within the article and its supplementary information files.

\section{Competing interests}

The authors declare that there is no conflict of interest.

\section{Sources of Funding}

This study was supported by the National Natural Science Foundation of China $(81941005,81970351$, 81822005), the Financial Grant from the key science and technology research and development plan of the Shaanxi province (2019ZDLSF01-01-01), and the Clinical Research Award of the First Affiliated Hospital of XJTU (XJTU1 AF-CRF-2017-006).

\section{Authors' contributions}


KG, and BLL designed this study, XPZ, LY, YBX,WYY and YW contributed to analysis and interpretation of data and were involved in revising the manuscript critically for important intellectual content. All authors read and approved the final manuscript.

\section{Acknowledgments}

We thank Biobank of First Affiliated Hospital of Xi'an Jiaotong University for data collection.

\section{Author details}

${ }^{1}$ Department of Cardiology, First Affiliated Hospital of Xi'an Jiaotong University, Xi'an, Shaanxi, Peoples R China; ${ }^{2}$ Key Laboratory of Molecular Cardiology of Shaanxi Province, Xi'an, Shaanxi, Peoples R China.

\section{References}

1. Brilakis ES, Mashayekhi K, Tsuchikane E, Abi Rafeh N, Alaswad K, Araya M, et al. Guiding Principles for Chronic Total Occlusion Percutaneous Coronary Intervention. Circulation. 2019;140(5):420-33.

2. Ramunddal T, Hoebers LP, Henriques JP, Dworeck C, Angeras O, Odenstedt J, et al. Chronic total occlusions in Sweden-a report from the Swedish Coronary Angiography and Angioplasty Registry (SCAAR). PLoS One. 2014;9(8):e103850.

3. Lee SW, Lee PH, Ahn JM, Park DW, Yun SC, Han S, et al. Randomized Trial Evaluating Percutaneous Coronary Intervention for the Treatment of Chronic Total Occlusion. Circulation. 2019;139(14):167483.

4. Tajti P, Alaswad K, Karmpaliotis D, Jaffer FA, Yeh RW, Patel M, et al. Procedural Outcomes of Percutaneous Coronary Interventions for Chronic Total Occlusions Via the Radial Approach: Insights From an International Chronic Total Occlusion Registry. JACC Cardiovasc Interv. 2019;12(4):346-58.

5. Azzalini L, Vo M, Dens J, Agostoni P. Myths to Debunk to Improve Management, Referral, and Outcomes in Patients With Chronic Total Occlusion of an Epicardial Coronary Artery. Am J Cardiol. 2015;116(11):1774-80.

6. Jang WJ, Yang JH, Choi SH, Song YB, Hahn JY, Choi JH, et al. Long-term survival benefit of revascularization compared with medical therapy in patients with coronary chronic total occlusion and well-developed collateral circulation. JACC Cardiovasc Interv. 2015;8(2):271-9.

7. Sanguineti F, Garot P, O'Connor S, Watanabe Y, Spaziano M, Lefevre T, et al. Chronic total coronary occlusion treated by percutaneous coronary intervention: long-term outcome in patients with and without diabetes. Eurolntervention. 2017;12(15):e1889-e97.

8. Stojkovic S, Juricic S, Dobric M, Nedeljkovic MA, Vukcevic V, Orlic D, et al. Improved Propensity-Score Matched Long-Term Clinical Outcomes in Patients with Successful Percutaneous Coronary Interventions of Coronary Chronic Total Occlusion. Int Heart J. 2018;59(4):719-26.

9. Elias J, van Dongen IM, Ramunddal T, Laanmets P, Eriksen E, Meuwissen M, et al. Long-term impact of chronic total occlusion recanalisation in patients with ST-elevation myocardial infarction. Heart. 
2018;104(17):1432-8.

10. Azzalini L, Dautov R, Ojeda S, Benincasa S, Bellini B, Giannini F, et al. Procedural and Long-Term Outcomes of Percutaneous Coronary Intervention for In-Stent Chronic Total Occlusion. JACC Cardiovasc Interv. 2017;10(9):892-902.

11. Libby P, Theroux P. Pathophysiology of coronary artery disease. Circulation. 2005;111(25):3481-8.

12. Seropian IM, Sonnino C, Van Tassell BW, Biasucci LM, Abbate A. Inflammatory markers in STelevation acute myocardial infarction. Eur Heart J Acute Cardiovasc Care. 2016;5(4):382-95.

13. Tanriverdi Z, Gungoren F, Tascanov MB, Besli F, Altiparmak IH. Comparing the Diagnostic Value of the C-Reactive Protein to Albumin Ratio With Other Inflammatory Markers in Patients With Stable Angina Pectoris. Angiology. 2020;71(4):360-5.

14. Verdoia M, Barbieri L, Di Giovine G, Marino P, Suryapranata H, De Luca G. Neutrophil to Lymphocyte Ratio and the Extent of Coronary Artery Disease: Results From a Large Cohort Study. Angiology. 2016;67(1):75-82.

15. Dong $\mathrm{CH}$, Wang ZM, Chen SY. Neutrophil to lymphocyte ratio predict mortality and major adverse cardiac events in acute coronary syndrome: A systematic review and meta-analysis. Clin Biochem. 2018;52:131-6.

16. Li C, Shen Y, Xu R, Dai Y, Chang S, Lu H, et al. Evaluation of Preprocedural Laboratory Parameters as Predictors of Drug-Eluting Stent Restenosis in Coronary Chronic Total Occlusion Lesions. Angiology. 2018:3319717752245.

17. Thygesen K, Alpert JS, Jaffe AS, Chaitman BR, Bax JJ, Morrow DA, et al. Fourth Universal Definition of Myocardial Infarction (2018). Circulation. 2018;138(20):e618-e51.

18. Patel KK, Arnold SV, Chan PS, Tang Y, Jones PG, Guo J, et al. Validation of the Seattle angina questionnaire in women with ischemic heart disease. Am Heart J. 2018;201:117-23.

19. Azzalini L, Carlino M, Bellini B, Marini C, Pazzanese V, Toscano E, et al. Long-Term Outcomes of Chronic Total Occlusion Recanalization Versus Percutaneous Coronary Intervention for Complex Non-Occlusive Coronary Artery Disease. Am J Cardiol. 2020;125(2):182-8.

20. Wilson WM, Walsh S, Hanratty C, Strange J, Hill J, Sapontis J, et al. A novel approach to the management of occlusive in-stent restenosis (ISR). Eurolntervention. 2014;9(11):1285-93.

21. Lee SH, Cho JY, Kim JS, Lee HJ, Yang JH, Park JH, et al. A comparison of procedural success rate and long-term clinical outcomes between in-stent restenosis chronic total occlusion and de novo chronic total occlusion using multicenter registry data. Clin Res Cardiol. 2020;109(5):628-37.

22. Jukema JW, Verschuren JJ, Ahmed TA, Quax PH. Restenosis after PCl. Part 1: pathophysiology and risk factors. Nat Rev Cardiol. 2011;9(1):53-62.

23. Wang Z, Liu C, Fang H. Blood Cell Parameters and Predicting Coronary In-Stent Restenosis. Angiology. 2019;70(8):711-8.

24. Yang $\mathrm{YL}, \mathrm{Wu} \mathrm{CH}$, Hsu PF, Chen SC, Huang SS, Chan WL, et al. Systemic immune-inflammation index (SII) Predicted Clinical Outcome in Patients With Coronary Artery Disease. Eur J Clin Invest. 
2020:e13230.

25. Fan Z, Luo G, Gong Y, Xu H, Qian Y, Deng S, et al. Prognostic Value of the C-Reactive Protein/Lymphocyte Ratio in Pancreatic Cancer. Ann Surg Oncol. 2020.

26. Goff DC Jr, Lloyd-Jones DM, Bennett G, Coady S, D'Agostino RB, Gibbons R, et al. 2013 ACC/AHA guideline on the assessment of cardiovascular risk: a report of the American College of Cardiology/American Heart Association Task Force on Practice Guidelines. Circulation. 2014;129(25 Suppl 2):49-73.

27. Kurtul A, Murat SN, Yarlioglues M, Duran M, Ergun G, Acikgoz SK, et al. Association of platelet-tolymphocyte ratio with severity and complexity of coronary artery disease in patients with acute coronary syndromes. Am J Cardiol. 2014;114(7):972-8.

28. Arbel Y, Finkelstein A, Halkin A, Birati EY, Revivo M, Zuzut M, et al. Neutrophil/lymphocyte ratio is related to the severity of coronary artery disease and clinical outcome in patients undergoing angiography. Atherosclerosis. 2012;225(2):456-60.

29. DiGangi C. Neutrophil-lymphocyte ratio: Predicting cardiovascular and renal complications in patients with diabetes. J Am Assoc Nurse Pract. 2016;28(8):410-4.

30. Arbel Y, Shacham Y, Ziv-Baran T, Laufer Perl M, Finkelstein A, Halkin A, et al. Higher neutrophil/lymphocyte ratio is related to lower ejection fraction and higher long-term all-cause mortality in ST-elevation myocardial infarction patients. Can J Cardiol. 2014;30(10):1177-82.

31. Zhang S, Diao J, Qi C, Jin J, Li L, Gao X, et al. Predictive value of neutrophil to lymphocyte ratio in patients with acute ST segment elevation myocardial infarction after percutaneous coronary intervention: a meta-analysis. BMC Cardiovasc Disord. 2018;18(1):75.

32. Nacar AB, Erayman A, Kurt M, Buyukkaya E, Karakas MF, Akcay AB, et al. The relationship between coronary collateral circulation and neutrophil/lymphocyte ratio in patients with coronary chronic total occlusion. Med Princ Pract. 2015;24(1):65-9.

33. Li C, Zhang F, Shen Y, Xu R, Chen Z, Dai Y, et al. Impact of Neutrophil to Lymphocyte Ratio (NLR) Index and Its Periprocedural Change (NLRDelta) for Percutaneous Coronary Intervention in Patients With Chronic Total Occlusion. Angiology. 2017;68(7):640-6.

34. Abdallah MS, Wang K, Magnuson EA, Spertus JA, Farkouh ME, Fuster V, et al. Quality of life after PCI vs CABG among patients with diabetes and multivessel coronary artery disease: a randomized clinical trial. Jama. 2013;310(15):1581-90.

35. Chan PS, Jones PG, Arnold SA, Spertus JA. Development and validation of a short version of the Seattle angina questionnaire. Circ Cardiovasc Qual Outcomes. 2014;7(5):640-7.

36. Safley DM, Grantham JA, Hatch J, Jones PG, Spertus JA. Quality of life benefits of percutaneous coronary intervention for chronic occlusions. Catheter Cardiovasc Interv. 2014;84(4):629-34.

37. Ybarra LF, Dautov R, Gibrat C, Dandona S, Rinfret S. Midterm Angina-Related Quality of Life Benefits After Percutaneous Coronary Intervention of Chronic Total Occlusions. Can J Cardiol. 2017;33(12):1668-74. 
Figures

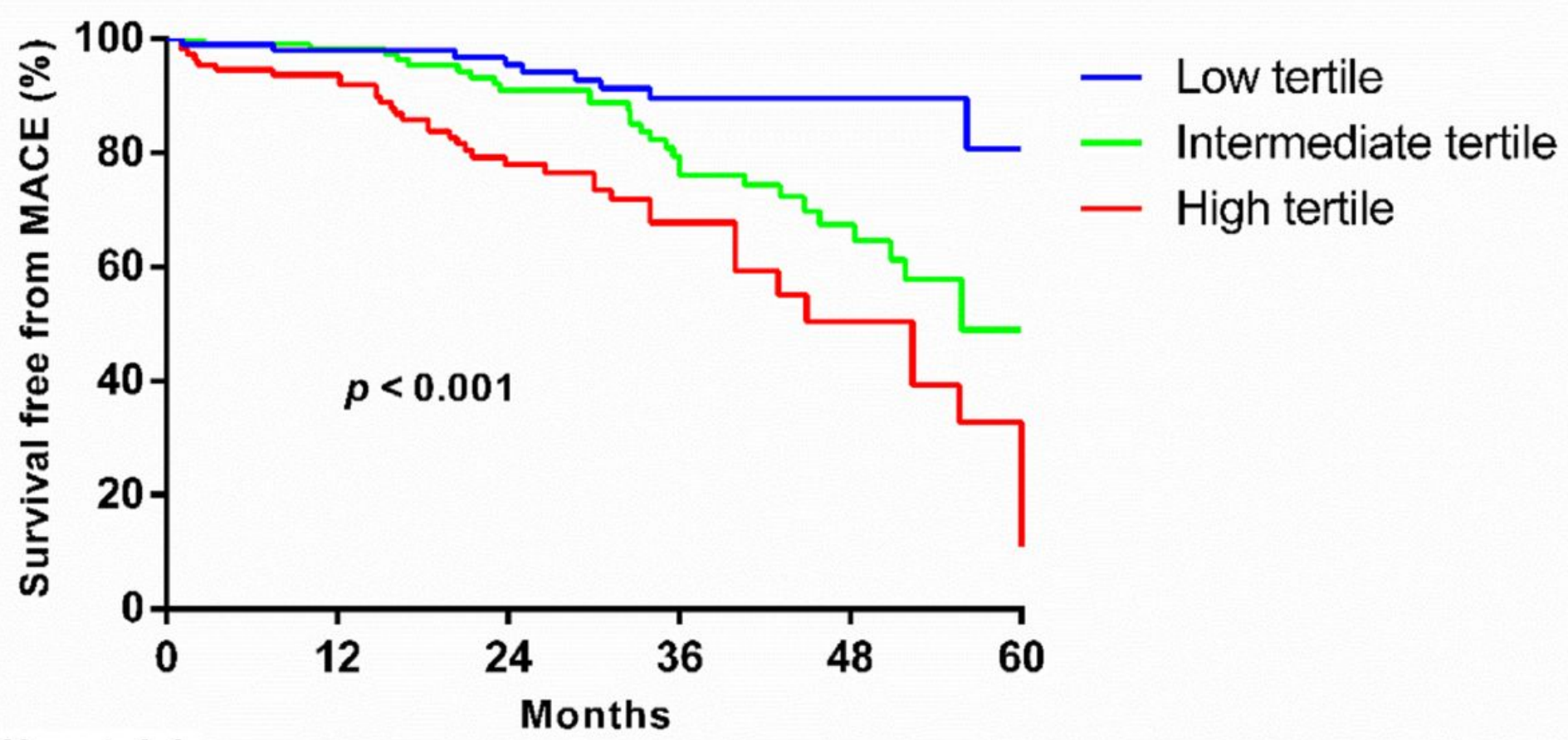

No. at risk

$\begin{array}{llllll}103 & 99 & 74 & 42 & 27 & 11 \\ 104 & 101 & 76 & 45 & 23 & 3 \\ 104 & 95 & 57 & 20 & 9 & 1\end{array}$

Figure 1

Kaplan-Meier curves for MACE according to tertiles of NLR level Kaplan-Meier curves describing the risk of MACE according to tertiles of baseline NLR level. MACE: major adverse cardiac events; NLR, neutrophillymphocyte ratio. 


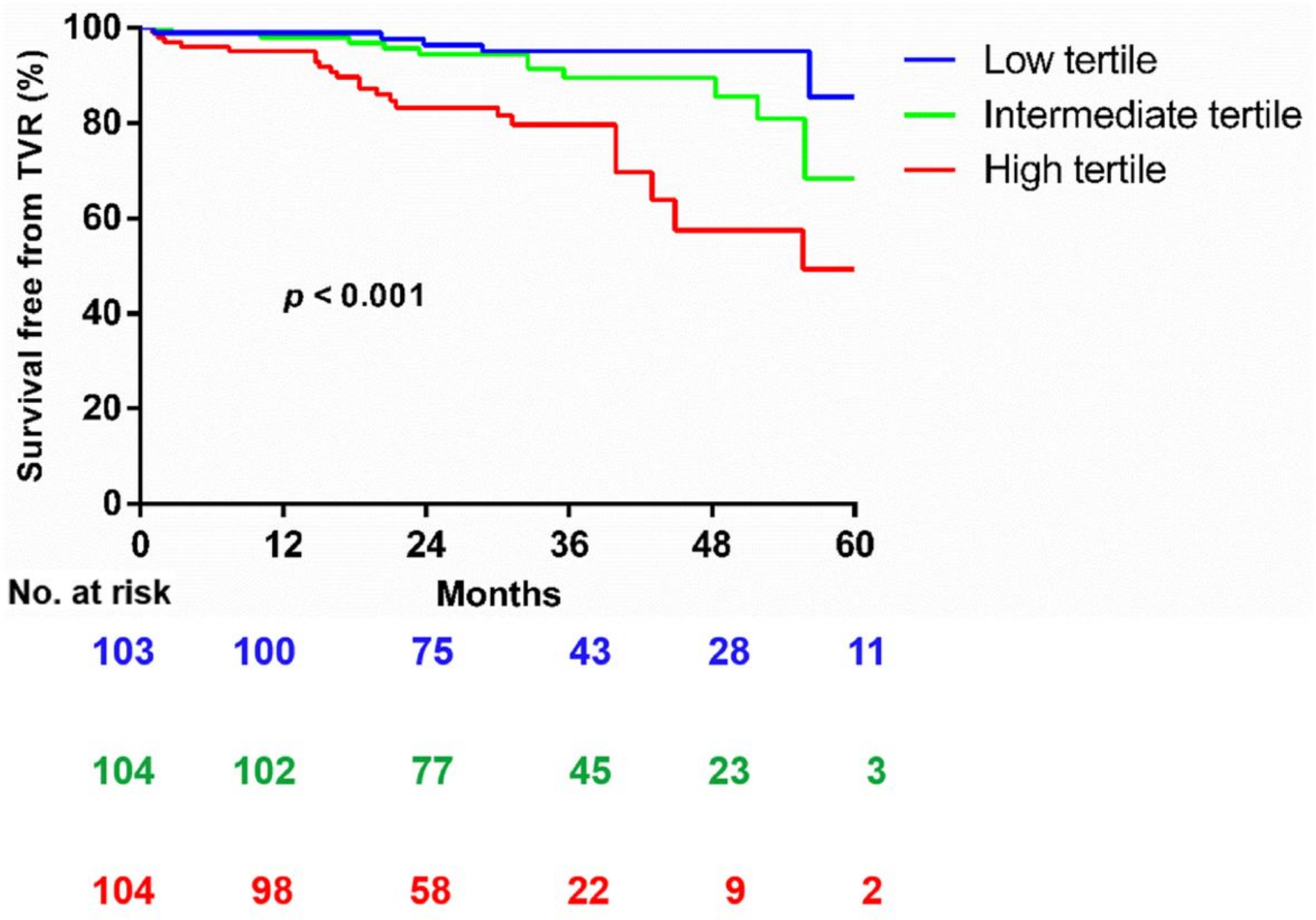

Figure 2

Kaplan-Meier curves for TVR according to tertiles of NLR level Kaplan-Meier curves describing the risk of TVR according to tertiles of baseline NLR level. TVR: target-vessel revascularization; NLR, neutrophillymphocyte ratio.

\section{Supplementary Files}

This is a list of supplementary files associated with this preprint. Click to download.

- Additionalfile1.docx 